International Egyptian Journal of Nursing Sciences and Research (IEJNSR)

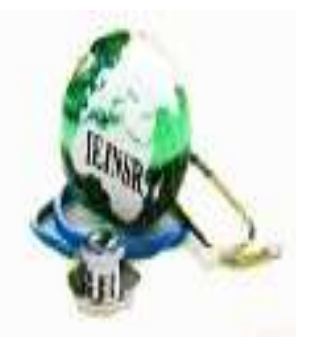

Received 2021-04-28

Accepted 2021-05-16

Review article

Published 1- 7-2021

\title{
Understanding Nausea and Vomiting of Pregnancy \& Hyperemesis Gravidarum and their management
}

Authors: Asmaa A . Abdelgelel

Lecturer of Woman's Health and Midwifery Nursing, Faculty of Nursing, Kafrelsheikh University

*Corresponding author: asmanour75@yahoo.com

\section{Introduction}

The medical condition of maximum, nausea and emesis throughout gestation is called Hyperemesis Gravidarum ( $\mathrm{H} \mathrm{G}$ ) . it's significant complication will include[ refractory emesis, dehydration, ketosis, electrolyte disturbance, and also, weight loss [less than five percent of prepregnancy weight (1).

\section{Definition}

The definition of $[\mathrm{HG}]$ is termed as persistent and excessive vomiting begins before the end of the [22nd] week of gestation; [HG] is also divided to mild and severe. The severe type has metabolic disturbances, such as [carbohydrate depletion, dehydration and also, electrolyte imbalance.

Anther definition of [ $\mathrm{HG}$ ] will be included persistent vomiting, large ketonuria, and weight loss, at least five percent of pre-pregnancy weight. Certain abnormalities such as [electrolyte, thyroid, and liver] may be present (2).

\section{Pathophysiology}

Understanding the pathophysiology of $[\mathrm{NVP} / \mathrm{HG}]$ is poor. Nowadays, HG is usually considered a disease of unknown pathophysiological origin. A complex interaction of [biological, psychological, and sociocultural factors] appeared to be the cause of [HG]. the following figure 2 summarized potential pathophysiological processes of[HG( 3).

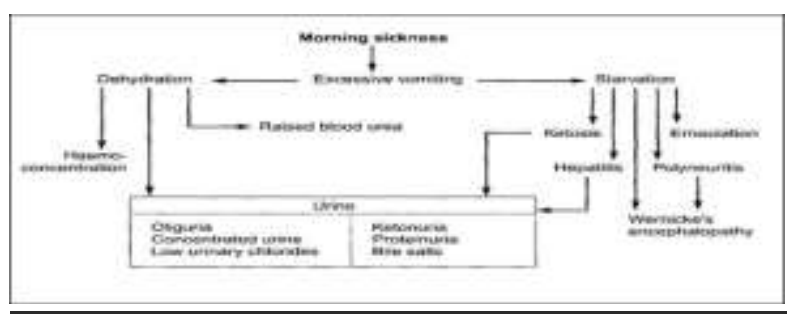

\section{Signs and symptoms}

The Signs and symptoms depends on the severity of of hyperemesis. In mild variety, there is vomiting throughout the day, but she can partially retained food. The vomit may be warty and contain ingested food. it become slightly 
bilious. There is slight tachycardia and mild dehydration. Blood pressure is maintained. Respiration is normal, urine acetone is negative ( 4).

In the moderate variety, the vomiting may become bilious and coffee ground. The pregnant woman is dehydrated, the tongue is dry, respiration may be acidotic and the breath smell acetone. There is tachycardia, the blood pressure is fall. Urine acetone is positive. There may be oliguria with raised blood urea. Serum sodium, potassium and chloride may be low(5)

In the sever variety pregnant woman is severely dehydrated with sunken eyes, breath smell acetone. Pulse and respiration is fast. Blood pressure is low. The patient may be jaundice. May be uremic or may have signs of peripheral neuritis or wernicke's encephalopathy. sensitivity to odors are a common complain of women with [HG ]. symptom experienced by some women suffering from [HG] are [Hyperolfaction. ptyalism or hypersalivation] (6) .

\section{Diagnosis of [HG]}

Classify the severity of [NVP] is diagnosed by[Pregnancy-Unique Quantification of Emesis (PUQE)] (7).

tools that are used for the assessment of [NVP/HG] severity are discussed as:

[Rhodes Index of Nausea (RINVR), Vomiting and Retching]: include eight questions about [duration/amount, frequency and distress caused by symptoms of nausea, vomiting and retching] for every: zero equal no symptoms, five equal worst possible symptoms and the Maximum score equal forty. Scores of more than thirty three indicated severe symptoms (8).

[Nausea and Vomiting of Pregnancy Instrument (NVPI)]: Three questions included as [nausea, retching and vomiting] through the past 7 days. For each question: zero equal no symptoms, five equal worst possible symptoms and finally Maximum score equal fifteen. More than eight indicates severe symptoms (9).
Hyperemesis Gravidarum possibly a complex condition and has been related to several risk factors . High pre-pregnancy body weight and nulliparity. are also noted as risk factors for [HG] include [maternal age younger than 20 years and twin gestation (10).

A better rate among certain racial/ethnic minority groups suggested by some proof. One study did note an increased risk among [Pacific Islander women Eskimo and Native American populations] tend to have a lower incidence of [HG] . 395 women with prolonged $\mathrm{HG}$ are being examined by Mullin et al as a risk factors of $\mathrm{HG}$. slightly younger and weighed more and had a history of allergies and a restrictive diet had been a women with prolonged HG (11) .

\section{Prognosis}

Fetal prognosis: exaggerated rate of prematurity, small for gestational age babies and also [APGAR] scores below seven to five min. had been a fetal prognosis in women with HG. association between severe nausea and vomiting in pregnancy and intrauterine growth restriction and low infant birth weight have been founded by researchers (12). In one study, younger age, lower socioeconomic status, primiparity, use of assisted reproductive technologies, substance abuse, and also chronic health conditions[e.g., diabetes, cardiovascular disease, mental illness] act as a pre-existing conditions for developing [HG] ( 13).

\section{Maternal prognosis}

Awater-soluble vitamin deficiency are called a multiple nutrient deficiencies particularly $\mathrm{B}$ complex, or vitamin B1, which may lead to persistent vomiting such as in HG. Wernicke's encephalopathy is a syndrome of multiple nutrient deficiencies particularly B complex, or vitamin B1 . neurologic symptoms of the pregnant woman may be present include[ lethargy ,confusion , hyporeflexia, ataxia, third cranial nerve symptoms as well as ophthamoplagia]. Wernicke's encephalopathy may lead to death in [HG] Whereas death related to $[\mathrm{HG}]$ is rare. (14 ).

\section{Risk factors for HG}


Deficiency of vitamin-K has been joined to complication similar to neonatal hemorrhage. intra-peritoneal hemorrhage intra-operatively in a young woman with large myoma and small bowel obstruction who had been diagnosed with hyperemesis caused by coagulopathy from vitamin $\mathrm{K}$ deficiency . This coagulopathy could result in exaggerated throughout procedures and surgeries needed throughout pregnancy (15).

\section{Intervention strategies for treatment of hyperemesis gravidarum}

Firstly: mild nausea and vomiting without dehydration

Diet and behavioral or lifestyle modification: [NVP] is treated with diet to avoid achieving the problem to $[\mathrm{HG}]$. choosing a bland diet, increasing carbohydrate intake, decreasing fat intake, avoiding offensive food odors, and also avoiding iron supplementation, if possible are recommended. till the nausea resolves, Omitting prenatal vitamins containing iron may be useful (16).

Frequent fluid intake is vital With episodic vomiting which has a danger signs of dehydration . minimize the metallic taste that women tend to develop in pregnancy is provided by cold fluids. (17).

Psychological support, family \& individual counseling, and a discount in demands of daily living and also environmental stimulation are methods recommended in reducing the effect of [HG]. The partner, spouse, friend, or alternative person ought to arrange meals because of the smell of hot or preparation food that may induces nausea. The pregnant women counseled to eat cold foods, such as sandwiches as ingestion hot foods cause patients to feel unwell. Fresh air, avoid fast movements, and sit upright for a few time when meals to avoid stomachic reflux are Behavioral changes counseled for pregnant woman with[ HG] (18).

\section{Complementary and alternative therapy(CAT) of HG}

Using CAT embrace several technique like acupressure, herbal therapy. Acupressure: involving applying of physical pressure to specific stylostixis points [eg, the Pericardium 6 [P6] is called Acupressure . it is useful for a few women with nausea in pregnancy to apply a Wristbands, that typically employed by passengers on boats to stop seasickness . P6acupressure can be used as an alternative means in reducing nausea, vomiting and retching episodes in women with HG( 19).

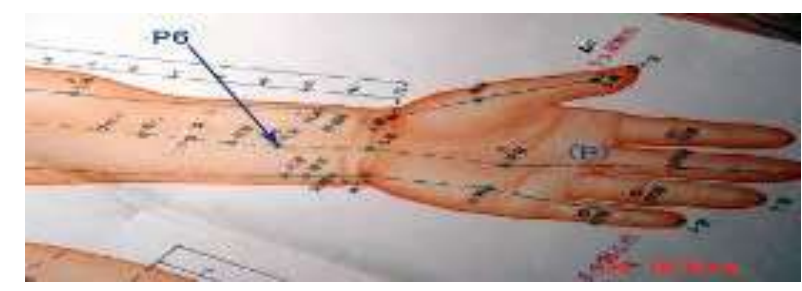

Ginger: antinausea properties were first delineated in ancient Chinese drugs that are in many preparations: powdered recent root, tablets, capsules, and syrup are called Ginger . in a minimum of thirty years the use of ginger as an antiemetic in NVP has been extensively investigated in clinical studies . that is suggested as a first-line of treatment for [NVP] . It doesn't seem to be related to exaggerated risk of adverse effects in maternity however it's going to inhibit platelet perform, and in theory may increase the danger of trauma. Therefore, ginger mustn't be employed in women susceptible to trauma abnormalities (20).

\section{Pharmacologic management}

- Serotonin antagonists [ondansetron] doesn't promote gastrointestinal motility and useful in cases of unconditioned reflex and regular symptoms so, it is not like metoclopramide. since the 1990s Zofran has been used for treatment of [HG]; no significant association between Zofran use and fetal malformations in case of further analysis in oversized 7,000 patients., the foremost prescribed medication for primary treatment of patients with [HG] is Zofran In the recent 
years. Also, the use of Zofran in maternity has not been shown to extend the chance of miscarriage, major malformations, or low birth weight (21) .

- Dopamine antagonists that act on the chemoreceptor trigger zone are called Phenothiazines that inhibit [NVP]. Aside impact from antipsychotic agent, the phenothiazines don't seem to be unremarkably prescribed for treatment of HG (22).

- Vitamin supplementation (Pabrinex I/II) will be required for all women with prolonged vomiting (e.g. women requiring IV fluids for more than 24 hours) and should be repeated at weekly intervals if the patient remains admitted for treatment of NVP or is readmitted with severe NVP (23).

- Intravenous therapy : infusion of Ringer's resolution with five-hitter dextroglucose (D5RL) is suggested over five-hitter dextroglucose in normal saline (D5NS), as a result of D5RL provides $\mathrm{P} \& \mathrm{Ca}$ supplements, whereas D5NS does not . Patient cannot tolerate oral liquids for a prolonged period or if clinical signs of dehydration are present, intravenous hydration ought to be used for the HG patient . treatment of [ketosis and vitamin deficiency] should be considered. Dextrose and vitamins, especially thiamine, ought to be enclosed within the therapy when prolonged vomiting is present (24) .

- Nutritional Support :is needed when the women not responding to IV rehydration and drugs. Patients would possibly receive parenteral nutrition [intravenous feeding via a PICC Line] - or enteral nutrition [via a NGT or a nasojejunal tube. Support the use of vitamin B6 to enhance the outcome is limited evidence from trials. Vitamin B1 and Folic Acid supplementation are recommended by Medical practitioner to prevent Wernicke's Encephalopathy (25).

\section{Termination of pregnancy(TOP)}

The Hyperemesis Education and Research Foundation in the USA reports that $10 \%$ of pregnancies complicated by $\mathrm{HG}$ finish in termination in women who would not otherwise have chosen this). Pregnancy Sickness Support within the UK found that several of those girls haven't been offered the total vary of treatments obtainable and fewer than $10 \%$ had been offered steroids. A medical specialty opinion ought to even be sought, and therefore the call for termination must be multidisciplinary, with documentation of therapeutic failure if this is often the explanation for the termination. Women ought to offered counseling before and after a decision of pregnancy termination is created (26).

\section{Discharge and follow-up}

Continue the antiemetics and access any care if the symptoms and/or signs recur are recommendations for the women who complain from [HG] At the time of discharg. Earlier treatment might cut back the requirement for hospital admission. Additionally higher communication and recommendation regarding the safety measure and proper antiemetics might modify the pregnant women to adequately support with HG. Determine a problem before vomiting is worsen, allowing earlier access for rehydration are done when checking for ketoaciduria . A follow-up in antenatal care is vital [ HG] (27).

A woman's [QOL] are often adversely affected by [NVP and HG] additionally, health care supplier ought to address the severity of a woman's symptoms in regard to her and social situation. impairing a woman's ability to perform on a daily basis, [QOL] and negatively affects relationships with the husband and family 
are negative impact of [NVP] that have been reported(28).

\section{References}

1. Abas MN, Tan PC, Azmi N, Omar SZ., (2015). Ondansetron compared with metoclopramide for hyperemesis gravidarum: a randomized controlled trial. Obstet Gynecol.;123(6):12721279.

2. Abramowitz A, Miller ES, Wisner KL.,(2017).Treatment options for hyperemesis gravidarum. Arch Womens Ment Health . 20: 363- 372.

3. Ahmed KT, Almashhrawi AA, Rahman RN, Hammoud GM, Ibdah JA; Almashhrawi; Rahman; Hammoud; Ibdah .,( 2013). "Liver diseases in pregnancy: diseases unique to pregnancy". World J Gastroenterol. 19 (43): 7639-46.

4. Akdemir, N.\& Bilir, C., (2011). Thyroid dysfunction in hyperemesis gravidarum: a study in Turkish pregnant women. J Turk Ger Gynecol Assoc. 12(3): 140-143.Published online 2011 Sep 1. doi: 10.5152/jtgga.2011.33

5. Thyroid dysfunction in hyperemesis gravidarum: a study in Turkish pregnant women

6. American College of Obstetricians and Gynecologists (ACOG).,(2015). Nausea and vomiting of pregnancy. Practice Bulletin No. 153. ObstetGynecol;126:e12-24

7. American College of Obstetrics and Gynecology (ACOG)., (2016). Practice Bulletin: nausea and vomiting of pregnancy. Obstet Gynecol. 103(4):803-14.

8. American Pregnancy Association., (2018). Hyperemesis gravidarum: sings, symptoms and treatment. http://americanpregnancy.org/pregnancycomplications/hyperemesis-gravidarum/ last updated July 2018.
9. American Medical Association (AMA), (2014). ICD-9-CM for Physicians, Volumes 1 \& 2, Professional Edition (Compact).available at https://books.google.com.eg/books?isbn= 032331996

10. Arab Millennium Development Goals Report. (2014): Facing challenges and looking beyond. New York: United Nations, League of Arab States; http://www.escwa.un.org/divisions/div_editor /Download.asp?table_name=divisions_other \&field_name=ID\&FileID=1559 (accessed 5 May 2014).

11. Association of Professors of Gynecology and Obstetrics., (2017). APGO Educational series on women's health issues. Nausea and vomiting of pregnancy. www.nationalperinatal.org/APGO accessed at may 2017.

12. Ayyavoo A1, Derraik JG, Hofman PL, et al., (2013). Severe hyperemesis gravidarum is associated with reduced insulin sensitivity in the offspring in childhood. J ClinEndocrinolMetab. 98(8):3263-3268.

13. Baba Y, Morisawa H, Saito K, Takahashi H, Rifu K, Matsubara S., (2016). Intraperitoneal hemorrhage in a pregnant woman with hyperemesis gravidarum: vitamin $\mathrm{K}$ deficiency as a possible cause. Case Rep Obstet Gynecol. doi: 10.1155/2016/5384943. Epub 2016 Aug 11.

14. Basirat Z, Moghadamnia AA, Kashifard M, Sarifi-Razavi A. (2015). The effect of ginger biscuit on nausea and vomiting in early pregnancy. Acta Med Iran;47:51-6.

15. Bazarganipour F, Mahmoodi H, Shamsaee B, Taghavi SA., (2015).The Frequency and 
Severity of Nausea and Vomiting during Pregnancy and its Association with Psychosocial Health. Journal of Midwifery and Reproductive Health. 3(3): 401-407

16. Biberoglu EH, Kirbas A, Dirican AO, et al., (2015).Alterations in lipid peroxidation and Tcell function in women with hyperemesis gravidarum. J Obstet Gynaecol. Sep 14.1-4.

17. Caitlin D,Katrina B, Jonathan M., (2018). Reviewing the effect of hyperemesis gravidarum on women's lives and mental health, British Journal of MidwiferyVol. 26, No. 2.

18. Cape AV, Mogensen KM, Robinson MK, Carusi DA.,(2014). Peripherally inserted central catheter (PICC) complications during pregnancy. JPEN J Parenter Enteral Nutr; 38:595.

19. Chhetry ,M. Thakur,A. Uprety, D K. Basnet, P. Joshi, R.,(2016). hyperemesis gravidarum a tertiary care center in Eastern Nepal J yub Med Coll Abbottabad .28(1) http://www.jamc.ayubmed.edu.pk.

20. Chortatos A, Haugen M, Iversen PO, Vikanes $\AA$ A, Eberhard-Gran M, Bjelland EK, Magnus P, Veierød MB., (2015). Pregnancy complications and birth outcomes among women experiencing nausea only or nausea and vomiting during pregnancy in the Norwegian Mother and Child Cohort Study. BMC Pregnancy Childbirth. ;15:138. doi: 10.1186/s12884-015-0580-6.

21. Chortatos, Haugen M , Iversen OP , Veierød MB. ,(2014).Dietary changes during first trimester pregnancy for women with nausea and vomiting in the Norwegian Mother and Child Cohort Study ,Norsk Epidemiologi . 24 (1-2): 147-153.

22. Clark S, Barbara H, McDonald SS., (2013). The impact of nausea and vomiting of pregnancy on quality of life: Report of a national consumer survey and recommendations for improving care. Obstetrical \& Gynecological Survey .68(9):S1-10.

23. Colodro-Conde L, Jern P,Johansson A, Sánchez-Romera JF, Lind PA, Painter JN, Ordoñana JR\&Medland SE., (2016). Nausea and Vomiting During Pregnancy is Highly Heritable. Behav Genet. 2016 Jul;46(4):48191. doi: 10.1007/s10519-016-9781-7. Epub 2016 Jan 22.

24. ACOG ., (2018). Committee on Practice Bulletins-Obstetrics Practice, Bulletin No. 189: Nausea And Vomiting Of Pregnancy. Obstet Gynecol; 131:e15.

25. Cox HC, Hinz MD, Scott Tilley D, Sridaromont KL, Maramba PJ., (2015) Clinical Applications of Nursing Diagnosis: Adult, Child, Women's, Psychiatric, Gerontic, and Home Health Considerations. 5th ed. Philadelphia, PA: FA Davis; 2015.

26. CunninghamF, et al. 2018.HER foundation. http://www.hyperemesis.org. last updated July 27/2018

http://americanpregnancy.org/pregnancycomplications/hyperemesis-gravidarum

27. D'Orazio LM, Meyerowitz BE, Korst LM, Romero R, Goodwin TM., (2011).Evidence against a link between hyperemesis gravidarum and personality characteristics from an ethnically diverse sample of pregnant women: a pilot study. J Womens Health (Larchmt). 20(1): 137-144.

28. David M, Borde T. Siedentopf F., (2012). Do immigration and acculturation have an impact on hyperemesis gravidarum? Results of a study in Berlin/Germany. J PsychosomObstetGynaecol. 33(2):78-84. 